\title{
Antibodies to a human liver membrane lipoprotein (LSP) in primary biliary cirrhosis
}

\author{
D tSANTOUlas, A PERPERAS, B PORTMANN, A L W F EDDLESTON, AND \\ ROGER WILLIAMS
}

From the Liver Unit, King's College Hospital and Medical School, London

SUMMARY Antibodies reacting with a human liver-specific membrane lipoprotein (LSP) have been detected using a sensitive and specific radioimmunoassay in $19(51 \%)$ of 37 patients with primary biliary cirrhosis. The anti-LSP antibodies were found only in the later stages of the disease as judged by histological criteria, being present in $73 \%$ of those in stage IV, $44 \%$ of those in stage III, and none of those in stage I or II. Although there was no relationship between percentage binding and standard liver function tests, there was a close correlation between percentage binding of ${ }^{125}$ I-LSP by serum and the extent of piecemeal necrosis of periportal hepatocytes on liver biopsy. The timing of the anti-LSP response makes it very unlikely that it is involved in the pathogenesis of the early bile duct damage but the results of this and other studies suggest that antibodies to this hepatocyte membrane lipoprotein may be an important cause of periportal liver cell necrosis in both primary biliary cirrhosis and chronic active hepatitis and could be one of the factors determining progression to cirrhosis in both these conditions.

The earliest histological lesion in primary biliary cirrhosis consists of a lymphocytic and plasma cell infiltrate with granuloma formation often associated with damaged interlobular bile ducts. ${ }^{1}$ Although these appearances are suggestive of an intense inflammatory process, the mechanisms responsible for the injury to the bile duct epithelium are not understood. The presence in the serum of an antibody reacting with mitochondria has pointed to the possible importance of autoimmunity in pathogenesis, but, as this antibody is directed at an antigen located on the inner membrane of the mitochondrion $^{2}$ and has no organ specificity, it seems unlikely that it could be effective in vivo in producing the localised liver lesion. It is more likely to be a consequence of the disease, perhaps being produced in response to an unusual microbial infection. ${ }^{3}$ Immune responses specifically directed at biliary antigens have recently been detected ${ }^{4}$ but the antigens involved are also found in other organs and it is again not clear what role these reactions have in pathogenesis. An unusual feature of the disease is the very high levels of circulating immune complexes, containing predominantly IgM antibody and it has been postulated that they could be involved in the bile duct injury. ${ }^{6}$

Received for publication 7 January 1980
Whatever the initial events, with progression of the disease the inflammatory infiltrate becomes more diffuse and cirrhosis eventually develops. In some cases the portal infiltrate breeches the limiting plate of the liver lobule and is associated with piecemeal necrosis of periportal hepatocytes, ${ }^{7}$ a feature which is more characteristic of chronic active hepatitis. Indeed, Doniach ${ }^{8}$ suggested that primary biliary cirrhosis and chronic active hepatitis may be at the opposite ends of a spectrum of autoimmune liver disease, sharing as they do several histological and immunlogical abnormalities. In chronic active hepatitis the periportal liver cell injury is associated with cellular and humoral immune responses to a liver-specific membrane lipoprotein (LSP) and there is strong circumstantial evidence that these may be responsible for the liver damage. ${ }^{9}$ Similar results have been reported in a small number of patients with primary biliary cirrhosis $^{1011}$ but the test systems used have been cumbersome and relatively insensitive.

In this study we have used a newly developed, sensitive, and specific radioimmunoassay ${ }^{12}$ to measure the levels of antibody to LSP in the sera of 37 patients with primary biliary cirrhosis and have analysed the results in relation to the histological findings on liver biopsy. 


\section{Methods}

Thirty-seven patients (29 females and eight males) with histological, biochemical, and immunological evidence of primary biliary cirrhosis were investigated. Their mean age was 56 years (range 37-72 years). Liver biopsy specimens at a date close to that of the serum sample (within six months) were examined independently by one of us (BP) without previous knowledge of biochemical or immunological test results. Each biopsy was assessed on a scale 0-3 for intensity of lymphocyte and plasma cell portal tract infiltrate and degree of piecemeal necrosis of hepatocytes, and was also classified according to the stage of the disease, ${ }^{1}$ including the presence of cirrhosis.

\section{RADIOIMMUNOASSAY FOR ANTI-LSP ANTIBODIES}

This is described elsewhere. ${ }^{12}$ In brief, duplicate $25 \mu \mathrm{l}$ samples of serum previously inactivated for 30 minutes at $56^{\circ} \mathrm{C}$ and diluted 1 in 20 in a borate/ EDTA buffer are incubated for three hours at $4^{\circ} \mathrm{C}$ with $2.5 \mathrm{ng}^{125} \mathrm{I}$-labelled liverspecific membrane lipoprotein. One milligram of dried staphylococcal cells (Sigma) is then added and incubated for another hour at $4^{\circ} \mathrm{C}$ to facilitate precipitation of the antibody- ${ }^{125}$ I-LSP complexes formed. Protein A, which is contained in the staphylococcal cell walls, avidly binds to the $\mathrm{Fc}$ region of $\mathrm{IgG} ;{ }^{13}$ $850 \mu$ l of a borate/EDTA buffer are then added to each tube to bring the final volume to $1.0 \mathrm{ml}$. After centrifugation at $20000 \times g$ for five minutes, $0.5 \mathrm{ml}$ of the supernatant are removed and this and the reaction mixture (including the pellet) are each counted in a gamma counter. The percentage of the ${ }^{125}$ I-LSP bound by antibody in the pellet is calculated according to the formula:

$$
\frac{\text { cpm lower } 0.5 \mathrm{ml}-\mathrm{cpm} \text { upper } 0.5 \mathrm{ml}}{\text { cpm lower } 0.5 \mathrm{ml}+\mathrm{cpm} \text { upper } 0.5 \mathrm{ml}} \times 100
$$

Blank samples not containing serum showed binding values of consistently less that $5 \%$.

\section{STATISTICAL METHODS}

Bivariate linear regression analysis was used to calculate $r$ values when percentage ${ }^{125}$ I-LSP binding was being compared with the results of tests in which an ordinal scale of measurement was available-for example, biochemical tests of liver function. As the histological findings were assessed on an interval scale, for comparisons using these results, $r$ values were determined from the nonparametric Spearman correlation coefficient.

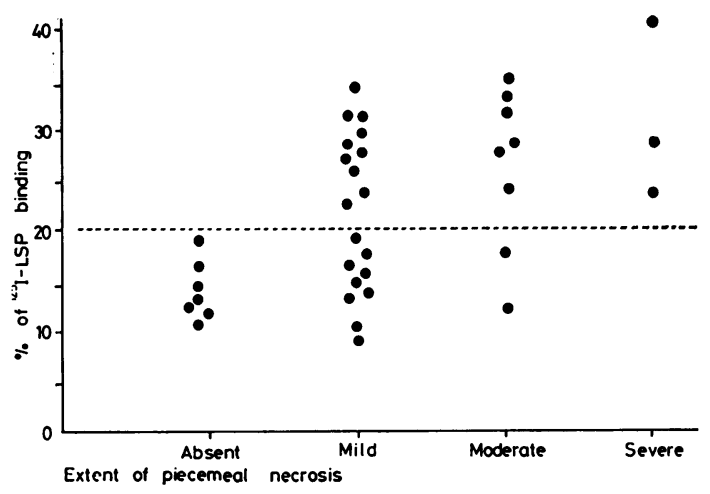

Fig. 1 The relationship between the results of the radio-immunoassy for antibodies to $L S P$ in serum expressed as percentage binding of ${ }^{125}$ I-LSP and the extent of piecemeal necrosis of periportal hepatocytes on liver biopsy in 37 patients with primary biliary cirrhosis. The dotted line indicates the upper limit of the normal range.

\section{Results}

The mean percentage binding of ${ }^{125}$ I-LSP by serum from 15 normal blood donors was $12 \cdot 7 \pm 2 \cdot 6 \%$ (SD) giving an upper limit of the normal range of $20.6 \%$ $($ mean $+3 \mathrm{SD})$. Binding values above this level were present in $19(51 \%)$ of the 37 patients with primary biliary cirrhosis.

When the binding of labelled LSP was analysed in relation to histological appearances on liver biopsy, a highly significant correlation was found with the extent of piecemeal necrosis of periportal hepatocytes (Fig. 1) $(r+0.58, P<0.001)$ but not with the intensity of the portal tract infiltrate $(r+0.29, \quad \mathrm{P}>0.05)$. Both piecemeal necrosis and high binding values were features found in the later stages of the disease (Figs 2 and 3), $73 \%$ of those with stage IV changes having increased ${ }^{125}$ I-LSP binding and $45 \%$ moderate or severe piecemeal necrosis compared with $44 \%$ and $11 \%$ respectively in stage III and none of those in stages I or II. As stage IV is defined by the presence of cirrhosis, these differences also reflected a relationship between this histological feature and the presence of both anti-LSP antibodies and periportal liver cell change. The correlation between ${ }^{125}$ I-LSP binding and piecemeal necrosis, however, was also independent of the presence of cirrhosis, the extent of piecemeal necrosis in stage IV cases with increased LSP binding being significantly higher than in those at the same stage but with normal binding values (Fig. 3, $\mathbf{P}<0.05$ by Wilcoxon rank sum test). There were no significant correlations between the binding of ${ }^{125}$ I-LSP and the serum levels of aspartate 


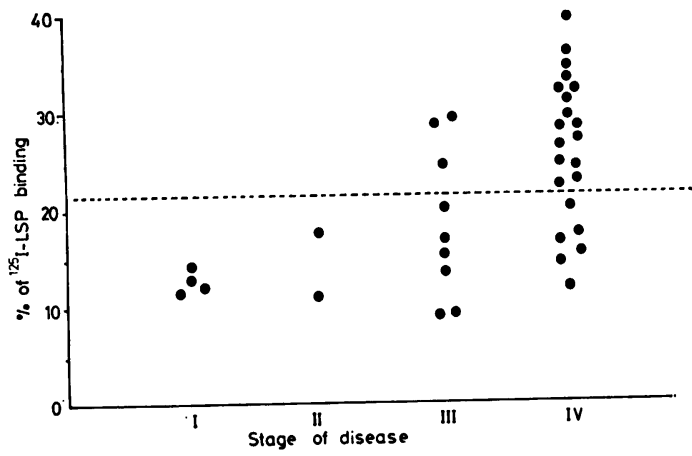

Fig. 2 The relationship between percentage binding of ${ }^{125}$ I-LSP and the stage of the disease as judged histologically. The dotted line indicates the upper linit of the normal range.

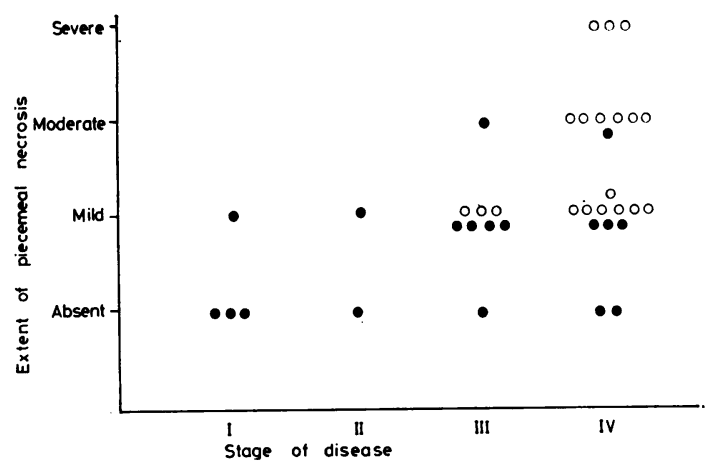

Fig. 3 The extent of piecemeal necrosis of periportal hepatocytes in relation to the stage of the disease as assessed histologically in liver biopsies from 37 patients with primary biliary cirrhosis. $\bigcirc=$ normal, $\bigcirc=$ increased ${ }^{125}$ I-LSP binding.

transaminase, alkaline phosphatase, bilirubin, IgM, or mitochondrial antibodies.

Because several patients were taking part in one of two double-blind trials of treatment, details of drug therapy were available in only 21 out of the 37 patients, but in these there was no evidence of an effect of the treatment on ${ }^{125}$ I-LSP binding.

Anti-LSP antibody was detected in three out of six patients receiving azathioprine, in four of eight being treated with penicillamine and in three of nine being given no anti-inflammatory or immunosuppressive drugs.

\section{Discussion}

The proportion of patients' sera with ${ }^{125}$ I-LSP binding values over the upper limit of the normal range in primary biliary cirrhosis $(51 \%)$ is lower than that found in chronic active hepatitis $(97 \%))^{9}$ but higher than that in an inactive cirrhosis such as haemochromatosis $(0 \%){ }^{9}$

In considering the importance of these results, two questions arise: does this antibody contribute to the liver damage, and why is it produced in some patients with primary biliary cirrhosis but not in others?

In chronic active hepatitis there is increasing evidence that anti-LSP antibodies may produce tissue damage, the first indication coming from the work of Meyer zum Büschenfelde and his colleagues in $1972,{ }^{14}$ who induced in rabbits inflammatory liver lesions similar to those found in chronic active hepatitis by prolonged immunisation with a mixture of human liver-specific antigens including the membrane lipoprotein. At this time LSP could not be isolated in a stable form but immunisation with a fraction depleted of the lipoprotein was relatively ineffective in inducing the liver damage, ${ }^{14}$ thus implicating LSP in the pathogenesis of the liver lesion. Direct comfirmation of this has come recently from Dr R Butler (personal communication) who produced the same lesion by immunisation with purified, stable LSP prepared by the method described by McFarlane et al. ${ }^{15}$ Evidence that anti-LSP antibodies can damage liver cells in vitro comes from Gonzales et al..$^{16}$ who demonstrated that isolated rabbit hepatocytes incubated with sera from patients with chronic active hepatitis became susceptible to damage by normal lymphocytes and also showed that this reaction could be blocked by prior absorption of the sera with LSP. These results have been confirmed in a different assay system by Vogten ${ }^{17}$ who showed that LSPcoated avian red blood cells incubated with sera from patients with chronic active hepatitis had increased ${ }^{51} \mathrm{Cr}$ release when cultured with normal lymphocytes. Finally, Jensen et al. $^{9}$ demonstrated a close correlation between the extent of periportal piecemeal necrosis on liver biopsy and anti-LSP antibody titre in untreated chronic active hepatitis, suggesting that these cytotoxic mechanisms may be operative in vivo. The present finding of an association between the binding of ${ }^{125}$ I-LSP by serum and the extent of piecemeal necrosis on liver biopsy in primary biliary cirrhosis offers further support for this concept while the lack of correlation with the intensity of the primary inflammatory infiltrate in the portal tracts underlines the specificity of the association with periportal liver cell damage.

The detection of anti-LSP antibodies and the associated piecemeal necrosis are both features which are found in the later stages of primary biliary cirrhosis and, although they may be of great importance in accelerating liver damage and possibly 
determining progression to cirrhosis, they must also be secondary in some way to the primary disease process. The absence of an anti-LSP response in patients with severe hepatic necrosis after an overdose of paracetamol ${ }^{9}$ argues against the proposition that this autoantibody is simply produced as a result of liver cell damage. Eddleston and Williams ${ }^{18}$ have suggested that in acute and chronic hepatitis, $T$ cells responding to viral-induced neo-antigens on the liver cell surface are responsible, by a 'helper' effect, for stimulating B cells responsive to unaltered liver membrane antigens including LSP. Granulomas usually contain activated $\mathrm{T}$ lymphocytes and Sanchez-Tapias et al., ${ }^{19}$ in an analysis of mononuclear cells released from disrupted liver biopsies showed the presence of such cells in liver tissue in primary biliary cirrhosis. It is possible that expansion of the initial granulomatous lesion eventually brings these activated $T$ lymphocytes into close contact with periportal liver cells and the T cells would then be able to exert their 'helper' effect to stimulate anti-LSP production. Other $T$ cells with suppressor effects normally act to limit the intensity of antibody responses ${ }^{20}$ and the defect in suppressor cell function recently demonstrated in some patients with primary biliary cirrhosis by Woltjen and Zetterman ${ }^{21}$ may further enhance the anti-LSP response.

We are grateful to the Wellcome Trust who supported this work

\section{References}

${ }^{1}$ Schaffner F. Primary Biliary Cirrhosis. Clin Gastroenterol 1975; 4: 351-67.

${ }^{2}$ Berg PA, Muscatello U, Horne RW, Roitt IM, Doniach D. Mitochondrial antibodies in primary biliary cirrhosis. II. The complement fixing antigen as a component of inner mitochondrial membranes. Br J Exp Pathol 1969; 50: 200-8.

${ }^{3}$ Doniach D, Walker JG. Immunology of liver disease. In: Popper H, Schaffner F, eds. Progress in liver diseases, Vol. IV. New York: Grune and Stratton, 1972: 385-97. 'McFarlane IG, Wojcicka B, Tsantoulas DC, Portmann BS, Eddleston ALWF, Williams R. Cellular immune responses to biliary antigens in primary biliary cirrhosis, sclerosing cholangitis and other chronic liver diseases. Gastroenterology 1980. (In press.)

${ }^{5}$ Wands JR, Dienstag JL, Bhan AK, Feller ER, Isselbacher KJ. Circulating immune complexes and complement activation in primary biliary cirrhosis. $N$ Engl $J$ Med 1978; 298: 233-7.

${ }^{6}$ Thomas HC, Potter BJ, Sherlock S. Is primary biliary cirrhosis an immune complex disease? Lancet 1977; 2: 1261-3.
${ }^{7}$ MacSween RNM, Berg PA. Autoimmune diseases of the liver. In: Ferguson A, MacSween RNM, eds. Immunological aspects of the liver and gastrointestinal tract. Lancaster: MTP Press, 1977: 345-86.

${ }^{8}$ Doniach D. The concept of an autoallergic hepatitis. Proc Roy Soc Med 1970; 63: 527-30.

${ }^{9}$ Jensen D, McFarlane IG, Portmann B, Eddleston ALWF, Williams R. Detection of antibodies directed against a liver-specific membrane lipoprotein in patients with acute and chronicactive hepatitis. $N$ Engl J Med 1978; 299: 1-7.

${ }^{10}$ Miller J, Smith MGM, Mitchell CG, Reed WD, Eddleston ALWF, Williams R. Cell-mediated immunity to a human liver-specific antigen in patients with active chronic hepatitis and primary biliary cirrhosis. Lancet 1972; 2: 296-7.

"Thomson AT, Cochrane AMG, McFarlane IG, Eddleston ALWF, Williams R. Lymphocyte cytotoxicity to isolated hepatocytes in chronic active hepatitis. Nature 1974; 252: 721-22.

${ }^{12}$ Jensen D, McFarlane IG, Nicholson A, Eddleston ALWF, Williams R. The development of a radioimmunoassay for the detection of antibodies to a liverspecific membrane lipoprotein (LSP). J Clin Lab Immunol 1978; 1: 31-5.

${ }^{13}$ Brunda MJ, Minden P, Sharpton TR. Precipitation of radiolabelled antigen-antibody complexes with protein A-containing Staphylococcus aureus. J Immunol 1977; 119: 193-8.

${ }^{14}$ Meyer zum Büschenfelde KH, Kössling FK, Meischer PA. Experimental chronic active hepatitis in rabbits following immunisation with human liver proteins. Clin Exp Immunol 1972; 11: 99-108.

${ }^{15}$ McFarlane IG, Wojcicka B, Zucker GM, Eddleston ALWF, Williams R. Purification and characterisation of human liver-specific membrane lipoprotein (LSP). Clin Exp Immunol 1977; 27: 381-90.

${ }^{16}$ Gonzales C, Cochrane AMG, Eddleston ALWF, Williams R. Mechanisms responsible for antibodydependent, cell-mediated cytotoxicity to isolated hepatocytes in chronic active hepatitis. Gut 1979; 20: 385-389.

${ }^{17}$ Vogten AJM. Results with LSP-coated target cells. In Eddleston ALWF, Weber JCP, Williams R, eds. Immune reactions in liver disease. Tunbridge Wells: Pitman Medical, 1979: 38.

${ }^{18}$ Eddleston ALWF, Williams R. Inadequate antibody response to HBAg or suppressor T-cell defect in development of active chronic hepatitis. Lancet 1974; 2 : 1543-5.

${ }^{19}$ Sanchez-Tapias J, Thomas HC, Sherlock S. Lymphocyte populations in liver biopsy specimens from patients with chronic liver disease. Gut 1977; 18: 472-5.

${ }^{20}$ Allison AC, Denman AM, Barnes RD. Cooperating and controlling function of thymus derived lymphocytes in relation to autoimmunity. Lancet 1971; 2: 135-40.

${ }^{21}$ Woltjen JA, Zetterman RK. Supressor T cell activity in primary biliary cirrhosis. Gastroenterology 1979; 76: 1301. (Abstract.) 